\title{
Cascaded Switched-Capacitor dc-dc Converters for a USB Power Delivery Compliant Charger
}

Overgaard, Jacob E. F.; Hertel, Jens Christian; Zsurzsan, Tiberiu-Gabriel; Zhang, Zhe

Published in:

Proceedings of 4 th IEEE International Future Energy Electronics Conference

Publication date:

2019

Document Version

Peer reviewed version

Link back to DTU Orbit

Citation (APA):

Overgaard, J. E. F., Hertel, J. C., Zsurzsan, T-G., \& Zhang, Z. (2019). Cascaded Switched-Capacitor dc-dc Converters for a USB Power Delivery Compliant Charger. In Proceedings of 4 th IEEE International Future Energy Electronics Conference IEEE.

\section{General rights}

Copyright and moral rights for the publications made accessible in the public portal are retained by the authors and/or other copyright owners and it is a condition of accessing publications that users recognise and abide by the legal requirements associated with these rights.

- Users may download and print one copy of any publication from the public portal for the purpose of private study or research.

- You may not further distribute the material or use it for any profit-making activity or commercial gain

- You may freely distribute the URL identifying the publication in the public portal 


\section{Cascaded Switched-Capacitor dc-dc Converters for a USB Power Delivery Compliant Charger}

\author{
Jacob E. F. Overgaard \\ Department of Electrical Engineering \\ Technical University of Denmark \\ Kongens Lyngby, Denmark \\ s144029@student.dtu.dk \\ Gabriel Zsurzsan \\ Department of Electrical Engineering \\ Technical University of Denmark \\ Kongens Lyngby, Denmark \\ tgzsur@elektro.dtu.dk
}

\author{
Jens Christian Hertel \\ Department of Electrical Engineering \\ Technical University of Denmark \\ Kongens Lyngby, Denmark \\ chrhert@elektro.dtu.dk \\ Zhe Zhang \\ Department of Electrical Engineering \\ Technical University of Denmark \\ Kongens Lyngby, Denmark \\ zz@elektro.dtu.dk
}

\begin{abstract}
The improvements in modern circuit technology reduce system size, improve the efficiency and reduce the cost. Utilization of soft-switching resonant power converters give high density high effeciency power converters for narrow output voltage ranges. To overcome this a cascaded switched-capacitor dc-dc converter is used to implement a Universal Serial Bus Power Delivery compliant charger. The converter uses a custom designed application specific integrated circuit designed for switched-capacitor dc-dc converters and wide bandgap technology allowing high frequency, high power design. The converter achieves peak efficiencies up to $98 \%$ at $60 \mathrm{~W}$ output power with a corresponding junction temperature of $50{ }^{\circ} \mathrm{C}$. Worst case junction temperatures reach $64^{\circ} \mathrm{C}$ and is viable for use in longterm battery charger systems. The cascaded power stages take up $14 \mathrm{~mm} \times 22 \mathrm{~mm}$.
\end{abstract}

Index Terms-Battery chargers, Switched mode power supplies, ASIC, Analog integrated circuit

\section{INTRODUCTION}

With the improvements in modern technology the world has seen an ever increasing demand for power supplies and battery chargers. The global battery charger sales have risen from a value of 10.18 billion USD in 2010 to a staggering 21.35 billion USD in 2018. With sales and the increase in global power bank market size at an expected 17.2 billion USD by 2020, the need for chargers are clear [1], [2].

As more OEM companies turn towards unified chargers like Universal Serial Bus (USB) Power Delivery (PD), all smartphones, tablets, laptops etc. now use the same plug which reduces the number of different chargers increasing popularity of USB-C chargers. The PD standard [3] specifies the following output voltages; $5 \mathrm{~V}, 9 \mathrm{~V}, 12 \mathrm{~V}, 15 \mathrm{~V}$ and $20 \mathrm{~V}$ for output currents up to $5 \mathrm{~A}$. The operating specifications aimed for in this work is $5 \mathrm{~V} 2 \mathrm{~A}, 12 \mathrm{~V} 3 \mathrm{~A}$ and $20 \mathrm{~V} 3 \mathrm{~A}$.

Resonant power converters utilizing a series-resonant tank have shown high efficiencies due to zero voltage switching
(ZVS) and zero current switching (ZCS) even with very high switching frequencies. Increasing switching frequencies reduces implementation size [4], [5]. To further reduce implementation cost, size and complexity self-oscillating gatedrives have become very popular [6]. The primary drawback of resonant converters is the high dependency upon load [7]. This load dependence makes the available output voltage regulation range narrow, reducing the operating efficiencies drastically outside the nominal operating point, rendering resonant power converters non-optimal for use in USB-PD compliant chargers.

To overcome this drawback, this work seeks to utilize downstream switched-capacitor dc-dc converters to implement a USB-PD compliant charger. A front-end resonant ac-dc converter is used to supply an output voltage range of $40 \mathrm{~V}$ to $48 \mathrm{~V}$ ensuring high efficiency within this output voltage range.

Utilizing switced-capacitor dc-dc converters improves efficiency and power density [8]-[10] and improves system integration [11], [12]. To further increase switching frequencies modern wide bandgap technologies are used. Wide bandgap increases device breakdown thresholds and reduces parasitic capacitances allowing for smaller and cheaper devices [7], [13]-[15].

To generate the USB-PD compliant voltages using switchedcapacitor converters, means to control the output voltage must be implemented. Three straightforward solutions exist:

- Vary the input voltage for a 2:1 switched-capacitor dc-dc converter from $10 \mathrm{~V}$ to $40 \mathrm{~V}$

- Implement gearbox control by including several flying capacitors

- Cascade two or three switched-capacitor dc-dc converters to implement 2:1, 4:1 and 8:1 conversion ratios

Each suggested implementation carries its own pros and cons. The first solution requires a front-end ac-dc converter with a wide range output voltage, heavily detoriating the 
efficiency of the ac-dc converter. With this required wide output voltage range of the ac-dc converter, the need for the switched-capacitor converter is virtually removed.

The second solution is widely used for implementing large output voltage ranges in integrated switched-capacitor dc-dc converters but is seldomly used for discrete implementations, due to the nature of the many power switches, flying capacitors and floating voltage domains [10].

The third solution investigated in this paper requires an output voltage variation from $40 \mathrm{~V}$ to $48 \mathrm{~V}$ from the frontend converter utilizing either $2: 1,4: 1$ or $8: 1$ conversion ratios from cascaded switched-capacitor converters utilizing wide bandgap gallium nitride field effect transistors (GaNFET) and an application specific integrated circuit (ASIC) for easing the switched-capacitor converter design.

The structure of this paper is divided into an introduction of the custom ASIC in Section II, the basic operation and mathematical derivation of switched-capacitor dc-dc converters in Section III, a study on power-transistors in Section IV, a discussion of the measurement results in Section $\mathrm{V}$ and lastly a conclusion in Section VI.

\section{ASIC IMPLEMENTATION}

Since switched-capacitor dc-dc converters often require several floating power devices and floating voltage domains, a custom ASIC was designed and manufactured in a TSMC $0.18 \mu \mathrm{m}$ process.

The ASIC features three $75 \mathrm{~V}$ set/reset triggered latch-based level-shifters presented in [16], [17]. The level-shifters are optimized for high speed, low power consumption and small chip area. Implemented on the same ASIC is four $5 \mathrm{~V}$ gatedrivers intended to drive light loads such as wide bandgap $\mathrm{GaN}$ devices or logic-level power transistors. The whole ASIC is designed to optimally operate in the frequency range of $100 \mathrm{kHz}-1 \mathrm{MHz}$ from a $5 \mathrm{~V}$ rail voltage.

Fig. II shows the active part of the ASIC that is implemented on a multi project wafer (MPW).

The active circuitry takes up $700 \mu \mathrm{m} \times 350 \mu \mathrm{m}$ corresponding to $0.245 \mathrm{~mm}^{2}$. The ASIC enables utilizing three floating voltage domains for floating transistors and is usable for both half-bridge and full-bridge power stages.

\section{SWITCHED-CAPACITOR DC-DC CONVERTER}

\section{A. Basic operation}

A 2:1 switched-capacitor dc-dc converter is depicted in Fig. 2. The circuit consists of four switches, $S_{1}$ through $S_{4}$ with resistance $R_{x}$, which can all be implemented with metal-oxidesemiconductor field-effect transistor (MOSFET) or GaNFET technology. The basic principle is as follows: During the first of two equally long states, $S_{1}$ and $S_{3}$ conduct charging the flying capacitor $C_{f l y}$ to $V_{\text {in }}-V_{\text {out }}$. During the second states $S_{2}$ and $S_{4}$ conduct, discharging $C_{\text {fly }}$ to $V_{\text {out }}$, here disregarding the ripple voltage of the flying capacitor.

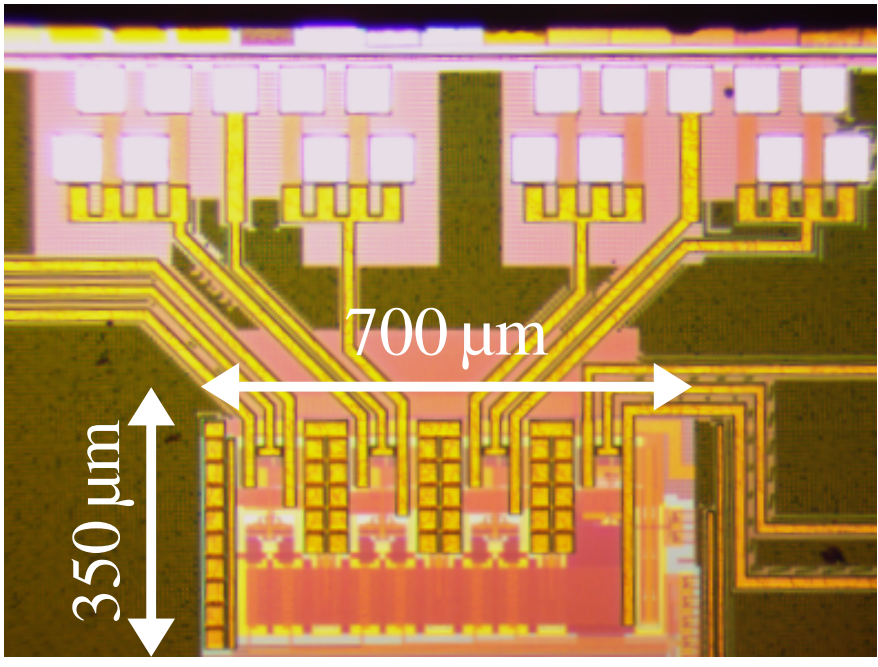

Fig. 1. Die photography. Three level-shifters and four gate-drivers in TSMC $180 \mathrm{~nm}$ process.

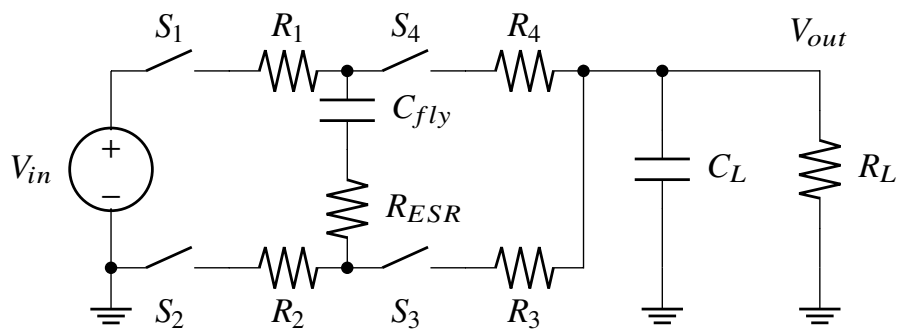

Fig. 2. Switched-capacitor dc-dc converter with a step-down ratio of 2:1.

This behaviour gives rise to a conversion ratio $M=\frac{1}{2}$ thus reducing the input voltage. The corresponding ripple voltage seen across $C_{f l y}$ is given by (1) [18].

$$
\Delta V_{c}=\left(V_{\text {in }}-2 V_{\text {out }}\right) \frac{1-e^{-1 /\left(2 f_{s w} R_{t o t} C_{f l y}\right)}}{1+e^{-1 /\left(2 f_{s w} R_{t o t} C_{f l y}\right)}}
$$

where $f_{s w}$ is the switching frequency and $R_{t o t}=R_{e s r}+2 R_{d s, o n}$ for which $R_{e s r}$ is the equivalent series resistance (ESR) of the flying capacitor and $R_{d s, o n}$ the switches' $\left(S_{1}-S_{4}\right)$ onresistance.

This charging and discharging behavior of $C_{f l y}$ results in the voltage depicted in Fig. 3. What is important to note from the figure is, how the specific frequency and capacitance are chosen gives rise to different waveforms across $C_{f l y}$. If the swtiching frequency is comparably low, the voltage will be much less linear. Choosing a comparably higher frequency will make the voltage more triangular.

The switched-capacitor dc-dc converter can in short be approximated by an equivalent output impedance $R_{e q}$ and a voltage conversion ratio denoted $M$ [19]. The simplification is depicted in Fig. 4.

\section{B. Mathematical derivation}

As the switched-capacitor converter in Fig. 2 is a 2:1 converter the conversion ratio is $M=1 / 2$. The corresponding 


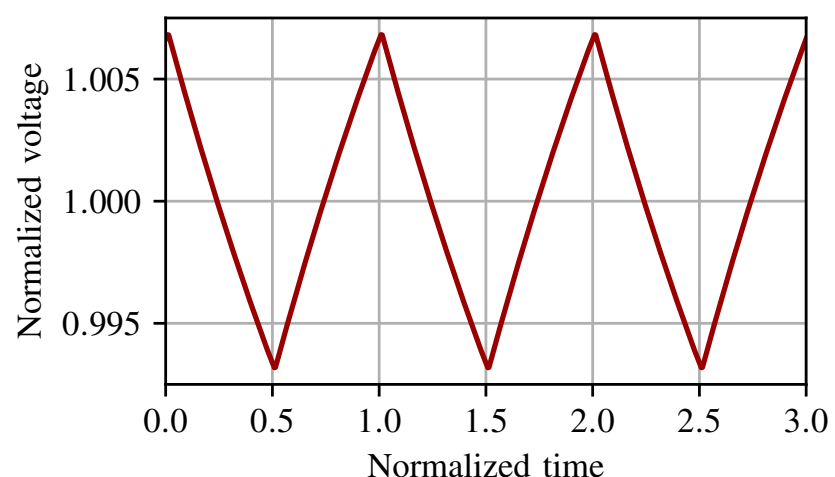

Fig. 3. Normalized flying capacitor voltage for a switched-capacitor dc-dc converter.

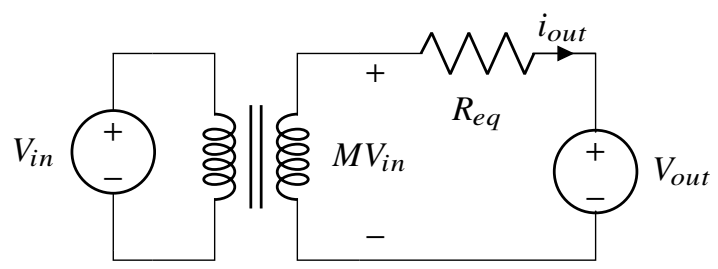

Fig. 4. Simplified model for a switched-capacitor converter with a voltage conversion ratio $M$ and output impedance $R_{e q}$.

$R_{e q}$ of the converter is a function of the flying capacitor, switches and switching frequency. To derive $R_{e q}$ the circuit will be analyzed utilizing the flow of charge as presented by [19].

A generic charge flow vector is shown in (2).

$$
\mathbf{a}^{(1 / 2)}=\left[\begin{array}{lllll}
q_{\text {out }}^{(1 / 2)} & q_{1}^{(1 / 2)} & \ldots & q_{n}^{(1 / 2)} & q_{\text {in }}^{(1 / 2)}
\end{array}\right] / q_{\text {out }}
$$

where $q_{\text {in }}$ is the input charge and $q_{\text {out }}$ is the output charge, of the given state (1/2). Correspondingly $q_{n}$ is the charge through device $n$. This could either be the charge flow through a resistor or a capacitor.

The charges through the corresponding resistances $R_{1}-R_{4}$ (which constitute the device $S_{1}-S_{4}$ on-resistances) and $R_{E S R}$ are analyzed by the charge flow vector in (3).

$$
\mathbf{a}_{r}=\left[\begin{array}{lllllll}
q_{\text {out }} & q_{1} & q_{2} & q_{\text {esr }} & q_{3} & q_{4} & q_{\text {in }}
\end{array}\right] / q_{\text {out }}
$$

Correspondingly the charge through the flying capacitor is given in (4).

$$
\mathbf{a}_{c}=\left[\begin{array}{lll}
q_{\text {out }} & q_{C_{f l y}} & q_{\text {in }}
\end{array}\right] / q_{\text {out }}
$$

To find the correct terms for the charge flow vectors, each individual state is investigated. Fig. 5 shows both of the individual states, charging $\phi_{1}$ and discharging $\phi_{2}$ of the flying capacitor.

Since all the output charge runs through $R_{1}, R_{E S R}$ and $R_{3}$ the corresponding charge vector is given in (5).

$$
\mathbf{a}_{r}^{(1)}=\left[\begin{array}{lllllll}
1 & 1 & 0 & 1 & 1 & 0 & 1
\end{array}\right] / 2
$$

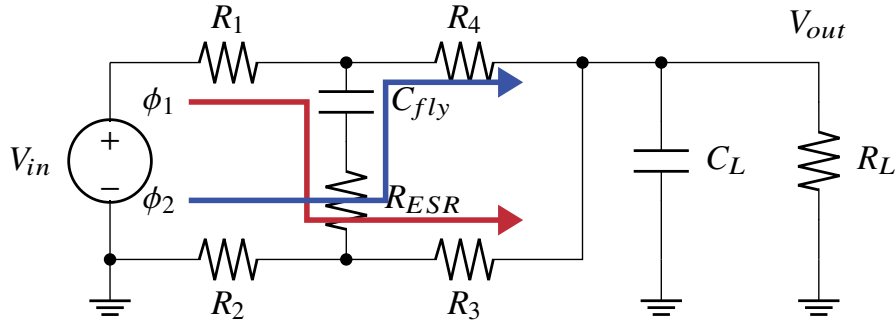

Fig. 5. Switched-capacitor operation states $\phi_{1}$ charging $C_{\text {fly }}$ and $\phi_{2}$ discharging $C_{f l y}$.

Looking at the capacitor charge, all the charge flows from input to output (positive) sign, and thus the corresponding charge vector for the capacitors is given in (6).

$$
\mathbf{a}_{c}^{(1)}=\left[\begin{array}{lll}
1 & 1 & 1
\end{array}\right] / 2
$$

For $\phi_{2}$ all the output charge runs through $R_{2}, R_{E S R}$ and $R_{4}$ yielding the charge vector shown in (7).

$$
\mathbf{a}_{r}^{(2)}=\left[\begin{array}{lllllll}
1 & 0 & 1 & -1 & 0 & 1 & 1
\end{array}\right] / 2
$$

For the flying capacitor, all the charge now runs from ground to the output and thus has a negative sign as per (8).

$$
\mathbf{a}_{c}^{(2)}=\left[\begin{array}{lll}
1 & -1 & 1
\end{array}\right] / 2
$$

Knowing these charge flow vectors, the equivalent output resistance $R_{e q}$ can be approximated by (9) [19].

$$
R_{e q}=\sqrt{R_{F S L}^{2}+R_{S S L}^{2}}
$$

Where $R_{F S L}$ corresponds to the fast switching limit and $R_{S S L}$ correspond to the slow switching limit [20]. The switching limits are given in (10) and (11) [20], [21].

$$
\begin{aligned}
R_{F S L} & =2 \sum_{i} R_{i} a_{r, i}^{2} \\
R_{S S L} & =\sum_{i=1}^{n} \frac{a_{c, i}^{2}}{f_{s w} C_{f l y, i}}
\end{aligned}
$$

Where $a_{c, i}$ and $a_{r, i}$ correspond to the $\mathrm{i}^{\text {th }}$ element of the capacitor or resistor charge vector respectively. These equations for $R_{F S L}$ and $R_{S S L}$ assume no dead-time and thus a $50 \%$ duty-cycle and an infinitely large output capacitor. Studies show better precision can be obtained taking dead-time and duty-cycle into consideration [21], [22].

With the equations (10) and (11), the fast switching limit and slow switching limit can be desribed in (12) and (13)

$$
\begin{aligned}
R_{F S L} & =2 R_{d s, o n}+R_{E S R} \\
R_{S S L} & =\frac{1}{4 C_{f l y} f_{s w}}
\end{aligned}
$$

The fast switching limit ultimately sets a limit for the absolute minimum output impedance and is determined by the choice of semiconductors $S_{n}$ and ESR of $C_{f l y}$. The slow switching limit correspond to the output impedance due to the non-linear charging and discharging of $C_{f l y}$. 


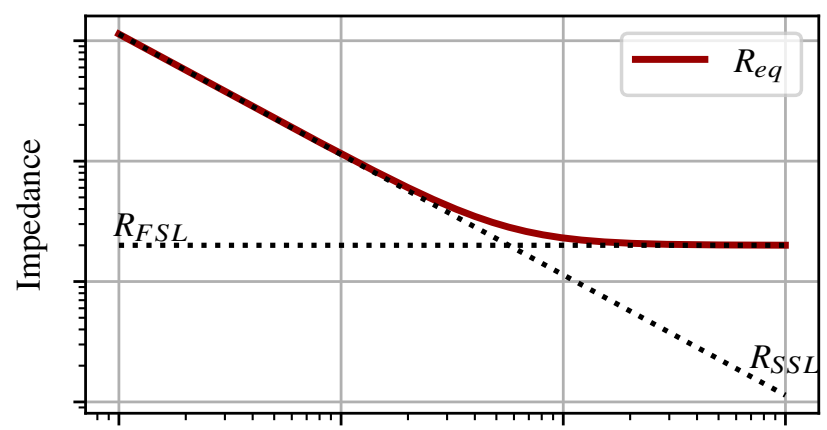

Frequency

Fig. 6. Conceptual plot of output impedance $R_{e q}$ of a switched-capacitor dc-dc converter vs. log-frequency.

TABLE I

USB-C VOLTAGES AND WHICH SWITCHED-CAPACITOR STAGE IS ENABLED

\begin{tabular}{|c|c|c|c|}
\hline Enabled stage(s) & $V_{\text {in }}$ & $V_{\text {out }}$ & $\boldsymbol{M}_{\boldsymbol{e q}}$ \\
\hline 3 & $40 \mathrm{~V}$ & $20 \mathrm{~V}$ & $1 / 2$ \\
\hline $3 \& 2$ & $48 \mathrm{~V}$ & $12 \mathrm{~V}$ & $1 / 4$ \\
\hline $3,2 \& 1$ & $40 \mathrm{~V}$ & $5 \mathrm{~V}$ & $1 / 8$ \\
\hline
\end{tabular}

How to balance between the two was presented in [21]. For switched-capacitor converters where there is negligible parasitic capacitive loading on the two nodes of $C_{f l y}$ to ground, the optimal relation between $R_{S S L}$ and $R_{F S L}$ is given in (14).

$$
R_{F S L}=R_{S S L}
$$

Since this application utilizes off-chip switching devices $S$, and off-chip flying capacitor for high power application, $C_{f l y}$ will inevitably end up in the range of several $\mu \mathrm{F}$. Since any parasitic capacitive loading of the flying capacitor's nodes will be in $\mathrm{pF}$, the parasitic capacitances will be negligible and the optimal balance between $R_{F S L}$ and $R_{S S L}$ given by (14) holds true.

Fig. 6 shows the conceptual output impedance vs. $\log$ frequency. As the figure depicts, by increasing the converter switching frequency the output impedance drops, until it reaches the fast switching limit $R_{F S L}$ which is dominated by the device resistances. Correspondingly for low frequencies, the output impedance is dominated by the non-linear charging and discharging of $C_{f l y}$.

\section{Cascading switched-capacitor stages}

The structure of cascading switched-capacitor dc-dc converters is depicted in Fig. 7.

To implement the correct voltages according to Section I, the cascaded switched-capacitor stages must be controlled according to Table I.

Thus to get the correct voltages, there must be a way for the output of each switched-capacitor stage to be fed to the corresponding USB output, which enables three discrete output voltages. The straightforward approach is to use low-resistance
TABLE II

CASCADED SWITCHED-CAPACITOR CONVERTER PERFORMANCE WITH DIFFERENT CONTROL SCHEMES FOR A $10 \mathrm{~W} 5 \mathrm{~V}$ OUTPUT.

\begin{tabular}{|c|c|c|c|}
\hline Control Scheme & $\phi$ & $R_{\text {eq, casc }}$ & $\eta$ \\
\hline FD & & $88 \mathrm{~m} \Omega$ & $94.28 \%$ \\
\hline PS & $\phi_{1}=0, \phi_{2}=90, \phi_{3}=180$ & $88 \mathrm{~m} \Omega$ & $92.9 \%$ \\
\hline PS & $\phi_{1}=180, \phi_{2}=90, \phi_{3}=0$ & $88 \mathrm{~m} \Omega$ & $93.2 \%$ \\
\hline PS & $\phi_{1}=0, \phi_{2}=90, \phi_{3}=0$ & $88 \mathrm{~m} \Omega$ & $93.35 \%$ \\
\hline
\end{tabular}

TABLE III

CASCADED SWITCHED-CAPACITOR CONVERTER DESIGN PARAMETERS.

\begin{tabular}{|c|c|c|c|}
\hline Parameter & Stage 1 & Stage 2 & Stage 3 \\
\hline$f_{\text {sw }}$ & $1 \mathrm{MHz}$ & $500 \mathrm{kHz}$ & $250 \mathrm{kHz}$ \\
\hline$C_{\text {fly }}$ & $5.6 \mu \mathrm{F}$ & $11 \mu \mathrm{F}$ & $22.3 \mu \mathrm{F}$ \\
\hline$R_{E S R}$ & $2.8 \mathrm{~m} \Omega$ & $2.8 \mathrm{~m} \Omega$ & $2.8 \mathrm{~m} \Omega$ \\
\hline$R_{\text {ds, on }}$ & $16 \mathrm{~m} \Omega$ & $16 \mathrm{~m} \Omega$ & $13.5 \mathrm{~m} \Omega$ \\
\hline
\end{tabular}

switches such as back-to-back PMOS/NMOS devices. The output impedance for each case can then be described as:

$$
\begin{aligned}
R_{e q, 20 V} & =R_{e q, 3} \\
R_{e q, 12 V} & =R_{e q, 2}+M^{2} R_{e q, 3} \\
R_{e q, 5 V} & =R_{e q, 1}+M^{2} R_{e q, 2}+M^{4} R_{e q, 1}
\end{aligned}
$$

where $M$ is the step-down ratio of each stage. This in turn yields (15) for $N$ cascaded switched-capacitor stages with output impedance $R_{e q}$ of stage $i$.

$$
R_{e q, \text { casc }}=\sum_{i=0}^{N-1} R_{e q, i} M^{2 i}
$$

These assumptions only hold true for infinitely high input impedances, which is naturally not achieved, but the implications of non-infinite input impedances is not significant.

When it comes to controlling each individual switchedcapacitor stage in Fig. 7, there is a variety of control methods. The two most obvious methods consist of frequency doubling (FD) between each stage or phase shift (PS) between each stage. The primary concern is to ensure a current-path from input to output in the case where multiple cascaded stages are used.

To test the two control methods LTSpice was used. Table II shows the results for the simulations. Here FD denotes frequency doubling for each subsequent stage, meaning stage 2 is the double frequency of stage 3 , and stage 1 is the double frequency of stage 2 . The chosen base frequency of stage 3 is $250 \mathrm{kHz}$. The parameter $\phi$ denotes the phase shift between each subsequent power stage. The chosen frequency utilizes the power transistors chosen in the Section IV.

From which it is clear that doubling the frequency for each subsequent stage yields the best performance. Utilizing the FD control method for the cascaded switched-capacitor stages the chosen system parameters are shown in Table III.

Since the design of the switched-capacitor converters is an iterative process, the $R_{d s, o n}$ of the switch devices found in following Section IV is included in Table III. 


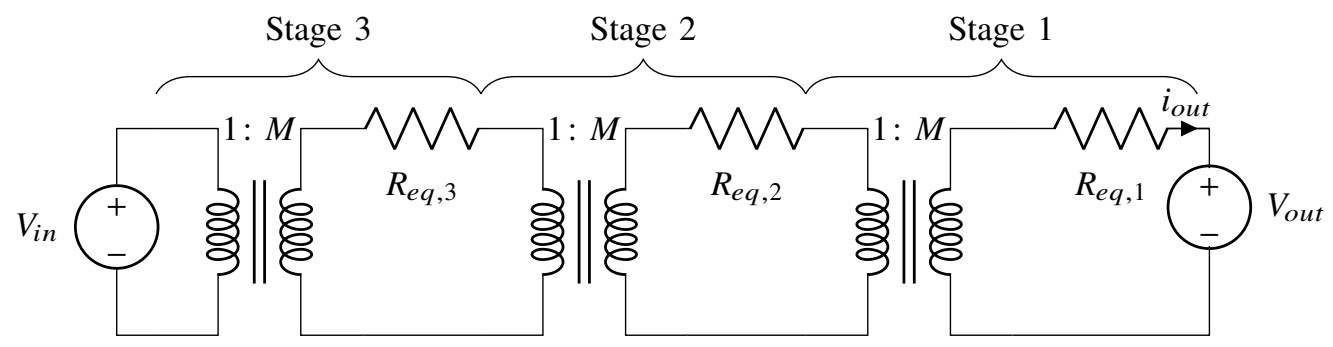

Fig. 7. Equivalent model of three cascaded switched-capacitor dc-dc converter stages. All $i$ converters have output impedance $R_{\boldsymbol{e}}, i$ and conversion ratio $M$.

TABLE IV

Power Transistor ReQUirements For EACH Power-Stage

\begin{tabular}{|c|c|c|}
\hline SC Stage & Voltage [V] & Average Current [A] \\
\hline 1 & 12 & 2 \\
\hline 2 & 30 & 3 \\
\hline 3 & 60 & 3 \\
\hline
\end{tabular}

\section{POWER Transistor Study}

For any power converter a key component is often the power transistor. Much of the converter stresses and limits are based on the power transistor, and the past years present interesting findings within new technologies like wide bandgap devices.

Choosing the right power transistor is not always straightforward, and many aspects must be kept in mind. A conservative approach is to find transistors that comply to voltage and current specifications and then looking at the figure-of-merits (FOM), that is most often defined by (16) and (17) [23], [24]

$$
\begin{aligned}
F O M_{1} & =R_{d s, \text { on }} Q_{g} \\
F O M_{2} & =R_{d s, \text { on }} Q_{o s s} \\
F O M & =F O M_{1}+F O M_{2}
\end{aligned}
$$

Where $R_{d s, o n}$ is the on-resistance of the power transistor, $Q_{g}$ the total gate charge and $Q_{o s s}$ the total output charge.

For this application there is a variety of voltage and current specifications set for each switched-capacitor converter, denoted SC Stage $x$, presented in Fig. 7. The specifications are given in Table IV with an additional safety margin of $20 \%$.

With these device specifications, a list of various devices can be investigated. Since the implemented ASIC is implemented in a $5 \mathrm{~V}$ process, the only devices of interest are GaNFETs and logic-level power MOSFETs.

Fig. 8 shows the combined FOM vs. area for some power switching devices that comply to the specs in Table IV. The figure shows some MOS devices beat the GaN devices on their total FOM, which is due to a very low FOM2 compared to GaNFETs, but have reasonably higher FOM1.

This means in general, the GaNFETs are much easier to drive, since their gate capacitance is smaller compared to the MOSFET counterparts. This has the benefit that they are better suited for high switching frequencies compared to the MOSFETs.

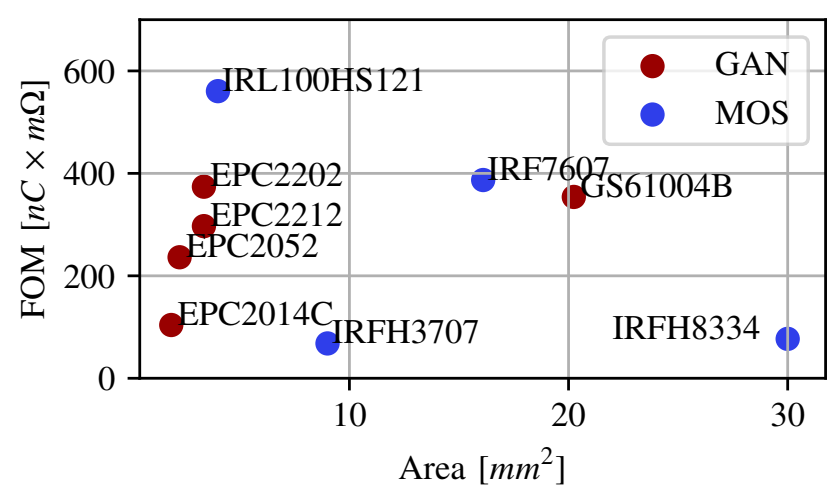

Fig. 8. Figure of merits for various logic level power-transistor MOSFETs and GaNFETs.

Since this application will utilize switching frequencies up to around $1 \mathrm{MHz}$, to achieve high power densities, small switching devices are desired and low gate-capacitances are required because of the ASIC's performance constraints, thus all the MOSFETs are ruled out leaving only $\mathrm{GaN}$ devices.

As there are various voltage requirements for each swichedcapacitor stage shown in Table IV, different transistors can be chosen if it is more beneficial to the overall design. The first GaNFET of interest is the EPC2014C which has the smallest package size and a total FOM around 100. This device tolerates up to $40 \mathrm{~V}$ and $10 \mathrm{~A}$ continuous, which fulfills the requirements for stage 1 and 2 but not 3 , which requires $60 \mathrm{~V}$ devices. However, choosing EPC2014C for the two viable stages will ensure a very small footprint size with the best performance.

The device chosen for stage 3 is the EPC2052, which is a $100 \mathrm{~V} 8.2 \mathrm{~A}$ rated device, which albeit is somewhat overrated but performs much better than the other devices and has a very small form factor similar to the EPC2014.

The switching devices chosen for each power-stage, the technology and their corresponding on-resistance are summarized in Table V.

Knowing the specific devices used for the switches enables us to utilize the equations derived in Section III-B to calculate the remaining parameters such as $f_{s w}$ and $C_{f l y}$ for each stage.

The parameters used for $f_{s w}$ and $C_{f l y}$ were previously listed in Table III. 
TABLE V

CHOSEN POWER TRANSISTORS FOR EACH SWITCHED-CAPACITOR STAGE.

\begin{tabular}{|c|c|c|c|}
\hline SC Stage & Device & Technology & $R_{\boldsymbol{d} \text { s, on }}$ \\
\hline 1 & EPC2014C & GaN & $16 \mathrm{~m} \Omega$ \\
\hline 2 & EPC2014C & GaN & $16 \mathrm{~m} \Omega$ \\
\hline 3 & EPC2052 & GaN & $13.5 \mathrm{~m} \Omega$ \\
\hline
\end{tabular}

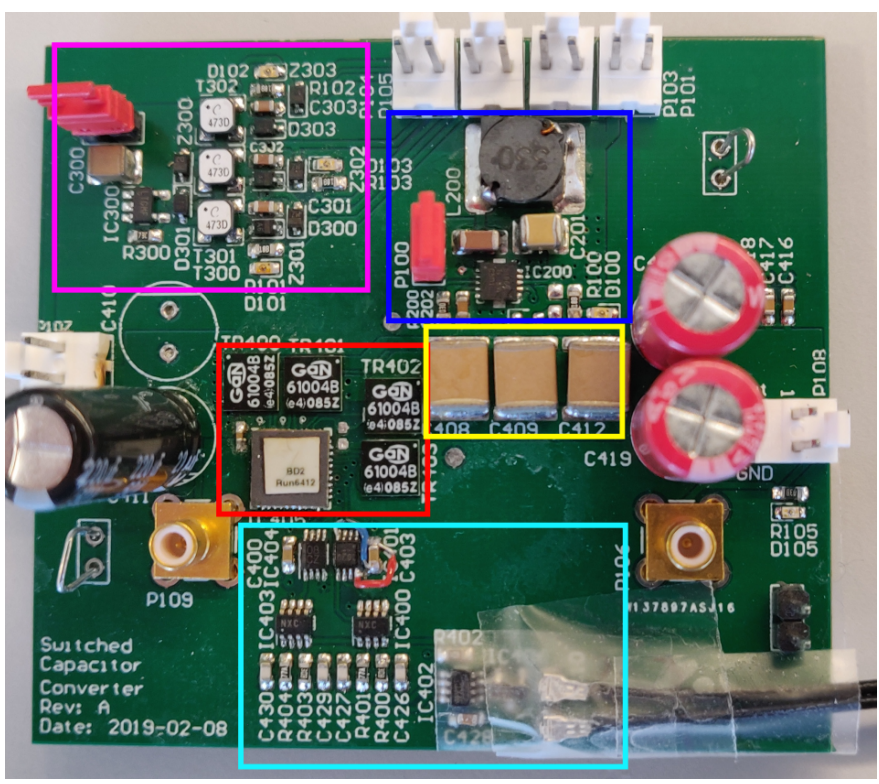

Fig. 9. Single stage switched-capacitor prototype. Power-stage (red), flying capacitor (yellow), floating voltage supplies (magenta), low voltage power supply (blue) and set/reset pulse generation (teal).

\section{Measurement Results}

Two different prototypes have been implemented. One prototype solely for measuring the output impedance to verify the mathematical model and one for implementing the dc-dc converter for generating USB-PD compliant voltages.

\section{A. Single Stage Prototype}

The first prototype addresses the modelling of the converter's output impedance and efficiency. It utilizes the designed custom ASIC, four GaNFET GS61004B switches and a $22 \mu \mathrm{F}$ flying capacitor.

The prototype is shown in Fig. 9. The prototype includes two different power supplies, one for generating floating voltages for the ASIC gate-drivers and one for low-voltage logic circuitry implementing non-overlapping clock pulses for the logic signals. The single stage prototype is designed to operate at $250 \mathrm{kHz}$.

To assess the output impedance the output voltage and current were measured using digital multimeters over a broad range of frequency. Fig. 10 shows the measured, simulated and calculated output impedance of the single stage prototype.

The measured output impedance corresponds to both the simulated and calculated output impedance for low frequencies. However, the measurements quickly deviate from the other graphs primarily due to the effects of the duty-cycle, caused by the implemented dead-time and partially due to

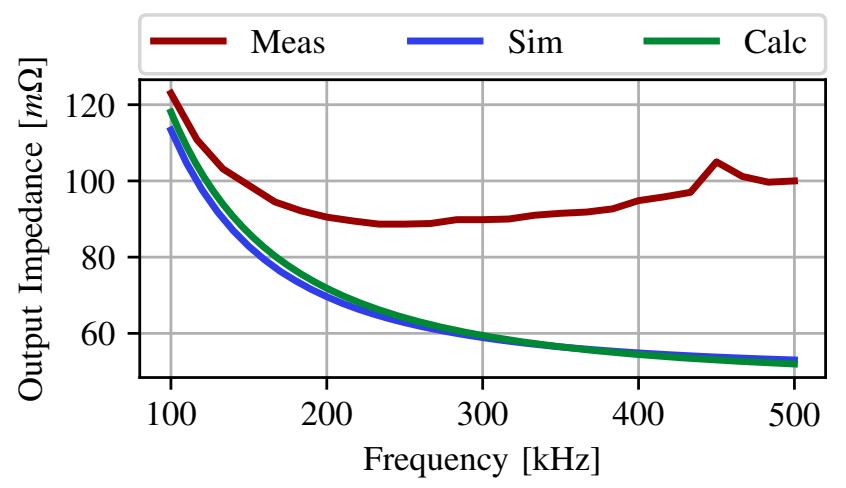

Fig. 10. Output impedance of a single stage switched-capacitor dc-dc converter prototype. The graph shows measured (red), simulated (blue) and calculated (green) output impedances.

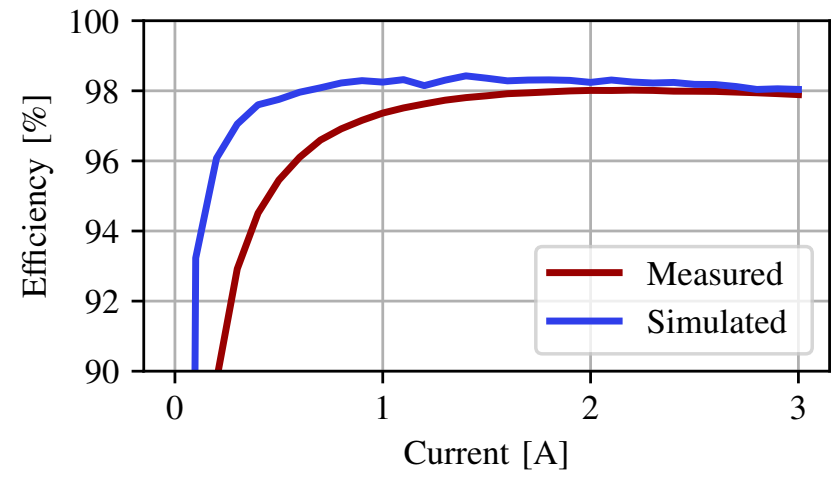

Fig. 11. Mesaused and simulated efficiency of a single stage switchedcapacitor converter for $40 \mathrm{~V}$ to $20 \mathrm{~V}$ conversion. Shows measured (red) and simulated (blue) efficiency across load current.

increased junction temperatures. The simulated and calculated output impedances are almost identical and proves the validity of the equations.

Similarly the efficiency of the single stage switchedcapacitor converter at $250 \mathrm{kHz}$ is measured. Fig. 11 shows the measured and simulated efficiency of the single stage converter. The measured efficency includes any power loss in the on-board power supplies, which is indicated by the deviation between the two curves at low output currents. At higher output currents the two curves converge and correspond well to each other.

With the use of a single stage switched-capacitor dc-dc converter the rough equations for the output impedance was tested and verified.

\section{B. Triple cascaded prototype}

The triple cascaded switched-capacitor dc-dc converter, which is the heart of this project, is the prototype that implements the switchable USB-PD compliant voltages. The prototype does not include any USB-C controller but only the required power-stage for generating the compliant voltages and currents. 


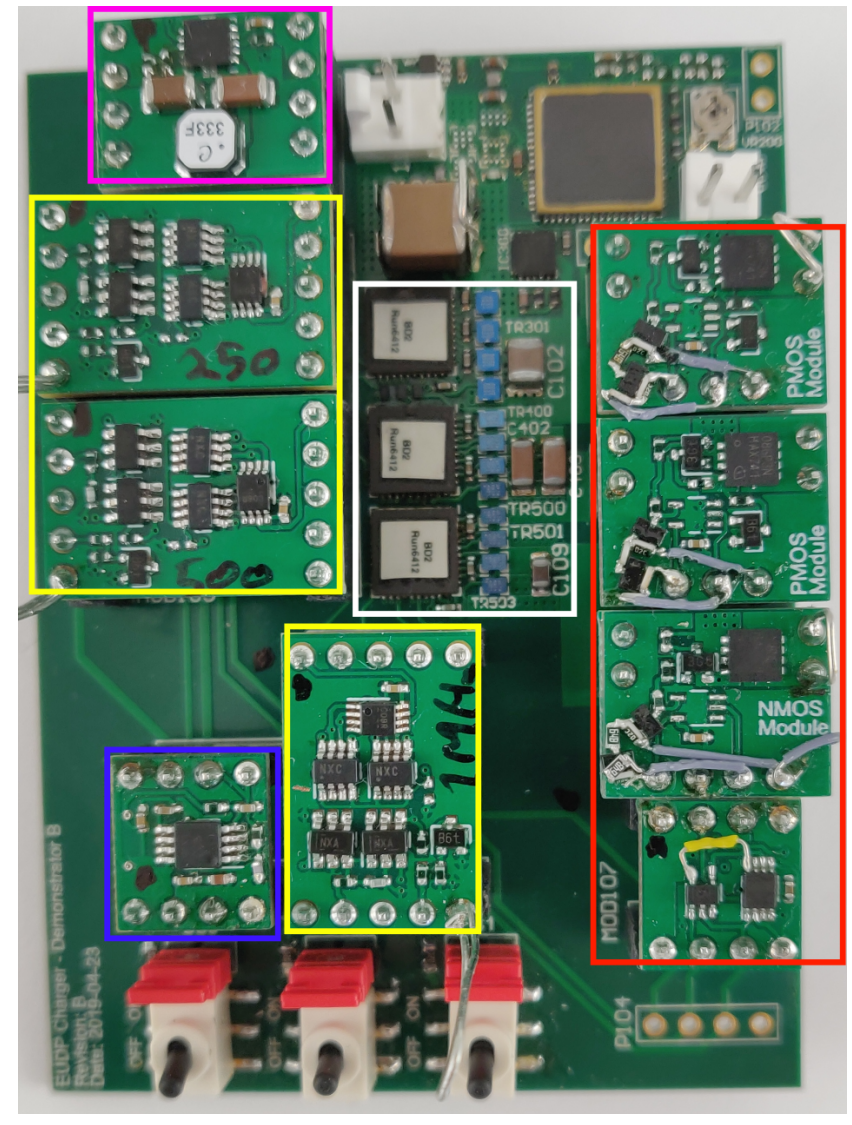

Fig. 12. USB-C PD compliant cascaded switched-capacitor dc-dc converters Switched-capacitor stages (white), clock generation (blue), set/reset pulse generators (yellow), bias power supply (magenta) and output control logic (red).

Fig. 12 shows the prototype of the cascaded switchedcapacitor dc-dc converters. The cascaded converters are shown in the white square and measure a total $14 \mathrm{~mm} \times 22 \mathrm{~mm}$ with two-layer component mounting. Support circuitry including clock generation and set/reset pulse generators also depicted on the prototype could for future iterations be included on the designed ASIC, further reducing the PCB area for implementing USB-PD compliant chargers. The output control logic shown in red is implemented with back-to-back MOSFETs ensuring the correct rail of one of the three cascaded switchedcapacitor converters are connected to the corresponding USBC output.

The cascaded prototype's efficiency is measured for the ranges given in Section I which is a part of the USB-PD compliance range.

Fig. 13 shows the measured and simulated efficiencies (including supply circuitry) for the three output voltages.

For a $20 \mathrm{~V}$ output where only stage 3 is running, the peak effeciency is $98 \%$. It reaches $95 \%$ for $12 \mathrm{~V}$ output and $86 \%$ for $5 \mathrm{~V}$ output. Both the $20 \mathrm{~V}$ and $12 \mathrm{~V}$ outputs achieve high efficiencies and are comparable to the expectations shown in simulations. However, the $5 \mathrm{~V}$ output does not achieve the expected $94 \%$ efficiency as achieved in the simulations. This deviation is likely caused by poor optimization of the duty-

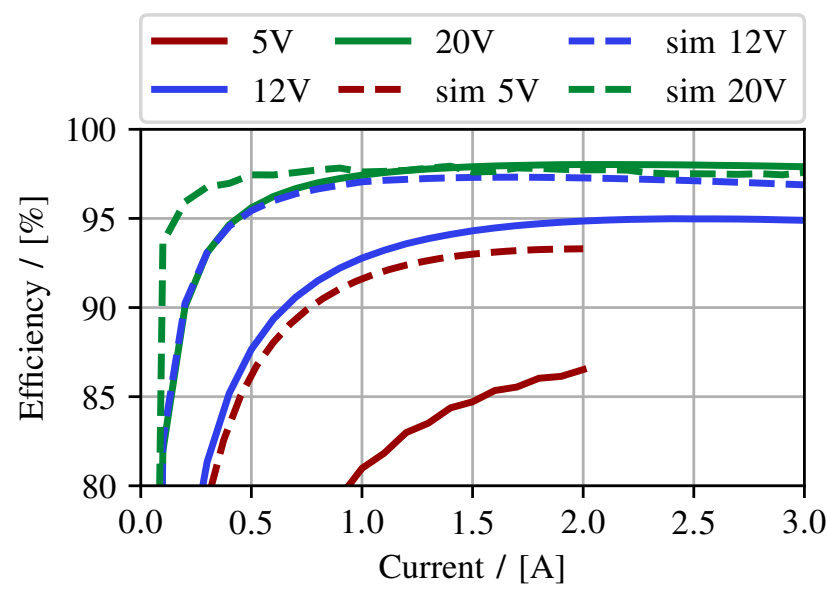

Fig. 13. Mesaused (solid lines) and simulated (dashed lines) efficiency of cascaded switched-capacitor dc-dc converters for $40 \mathrm{~V}$ input and $5 \mathrm{~V}$ (red), $12 \mathrm{~V}$ (blue) and $20 \mathrm{~V}$ (green) output voltages.

cycles of phase 1 and phase 2 of switched-capacitor stage 1 . If both states are not enabled equally long, the prior assumptions and formula are no longer true.

For all three output voltages the temperatures of the corresponding stages were measured. Fig. 14, 15 and 16 show the operating temperature of the corresponding switched-capacitor stages.

The peak temperature reached is $64{ }^{\circ} \mathrm{C}$ of the second switched-capacitor stage utilized for a 4:1 step-down ratio for $12 \mathrm{~V}, 36 \mathrm{~W}$ out. As the figures depict, the GaNFETs are the devices that reach the highest temperatures. A peak operating temperature of $64^{\circ} \mathrm{C}$ is well below the temperature recommendations for the GaNFETs and also below any significant long term derating effects. This in turn means a long-term reliable USB-PD charger can be implemented with GaN technology, given all external circuitry provide long-term stability as well.

\section{CONCLUSION}

The improvement in mordern integrated circuit technologies allow small and efficient systems for high power systems including power supplies and battery chargers. Resonant power converters is one topology offering high efficiencies for very narrow output voltages.

As the Universal Serial Bus (USB) Power Delivery (PD) require a wide output voltage range, this paper presents the use of gallium nitride field effect transistors and an application specific integrated circuit level-shifter and gate-driver for implementation of a down-stream dc-dc switched-capacitor converter

The first prototype illustrates the overall design procedure which yields great performance and a low output impedance. Additionally the application specific integrated circuit proved useful in implementing a high performance switched-capacitor dc-dc converters with little circuit complexity.

The second prototype implemented a charger utilizing a cascaded setup of switched-capacitor dc-dc convertes with a 2:1 step-down ratio and series pass switches to implement 

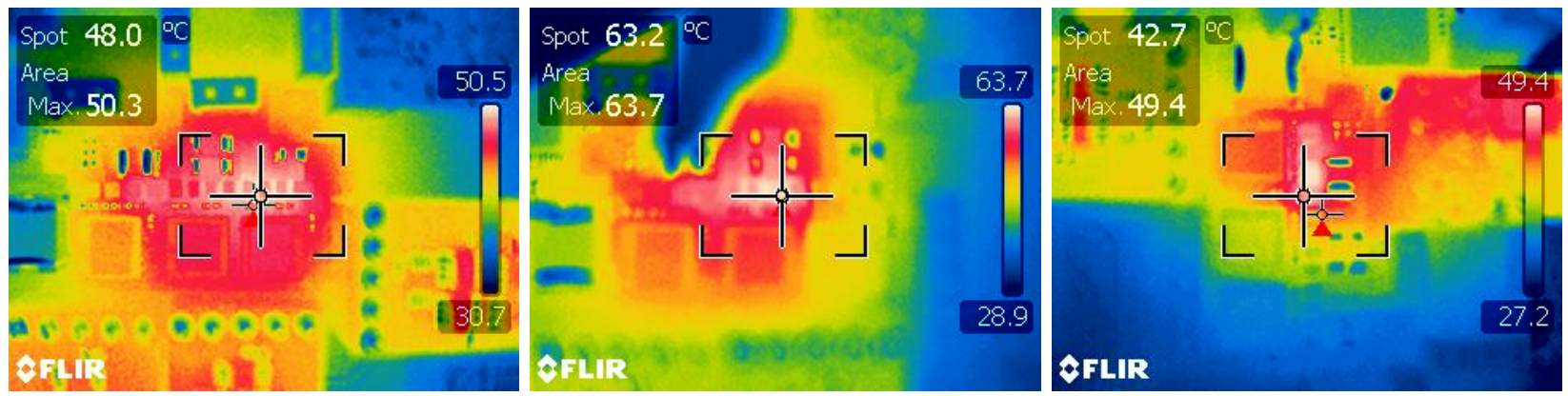

Fig. 14. $5 \mathrm{~V}, 10 \mathrm{~W}$ output, max temperature of Fig. $15.12 \mathrm{~V}, 36 \mathrm{~W}$ output, max temperature Fig. $16.20 \mathrm{~V}, 60 \mathrm{~W}$ output, max temperature stage 1 of $50^{\circ} \mathrm{C}$

of stage 2 of $64^{\circ} \mathrm{C}$.

of stage 3 of $50^{\circ} \mathrm{C}$

USB-PD compliant output voltages of $5 \mathrm{~V}, 12 \mathrm{~V}$ and $20 \mathrm{~V}$. The charger reached an efficiency of $98 \%$ at $60 \mathrm{~W} 20 \mathrm{~V}$ output and $86 \%$ at $10 \mathrm{~W} 5 \mathrm{~V}$, including external control and logic circuitry.

Active power-stage circuitry with dimensions of $14 \mathrm{~mm} \times$ $22 \mathrm{~mm}$ reached worst-case peak temperatures of $64^{\circ} \mathrm{C}$ and best-case full power temperatures of $50^{\circ} \mathrm{C}$ which is well within any temperature limits of modern wide bandgap devices.

\section{ACKNOWLEDGEMENT}

This work was supported by the danish Energy Development and Demonstration Platform (EUDP) journal number 64014-0558.

\section{REFERENCES}

[1] "Global battery charger sales value from 2010 to 2018 (in billion U.S. dollars)." [Online]. Available: https://www.statista.com/statistics/674177/battery-charger-salesvalue-worldwide/

[2] "Global Power Bank Market Size is Expected to Reach USD 17.2 Billion by 2020," Deerfield Beach, may 2017. [Online]. Available: https://www.globenewswire.com/newsrelease/2017/05/19/988217/0/en/Global-Power-Bank-Market-Size-isExpected-to-Reach-USD-17-2-Billion-by-2020.html

[3] U. I. F. Inc., "Universal Serial Bus Power Delivery Specifications Rev 3.0 Ver. 1.2," USB Implementers Forum, Tech. Rep., 2018.

[4] J. M. Rivas, Y. Han, O. Leitermann, A. D. Sagneri, and D. J. Perreault, "A high-frequency resonant inverter topology with low-voltage stress," IEEE Transactions on Power Electronics, vol. 23, no. 4, pp. 1759-1771, jul 2008.

[5] J. C. Hertel, J. E. F. Overgaard, I. H. H. Jørgensen, T. M. Andersen, M. Rødgaard, and A. Knott, "Synchronous Rectifier for High-Frequency Switch Mode Power Supplies using Phase Locked Loops Synchronous Rectifier for High-Frequency Switch Mode Power Supplies using Phase Locked Loops," 2019 IEEE Journal of Emergin and Selected Topics in Power Electronics, oct 2019.

[6] M. P. Madsen, J. A. Pedersen, A. Knott, and M. A. E. Andersen, "Selfoscillating resonant gate drive for resonant inverters and rectifiers composed solely of passive components," IEEE Applied Power Electronics Conference and Exposition - APEC, pp. 2029-2035, mar 2014.

[7] A. Knott, T. M. Andersen, P. Kamby, J. A. Pedersen, M. P. Madsen, M. Kovacevic, and M. A. E. Andersen, "Evolution of Very High Frequency Power Supplies," Emerging and Selected Topics in Power Electronics, IEEE Journal of, vol. 2, no. 3, pp. 386-394, dec 2014.

[8] M. Chen, K. K. Afridi, and D. J. Perreault, "Stacked switched capacitor energy buffer architecture," IEEE Transactions on Power Electronics, vol. 28, no. 11, pp. 5183-5195, feb 2013.

[9] Y. Lei and R. C. N. Pilawa-Podgurski, "A general method for analyzing resonant and soft-charging operation of switched-capacitor converters," IEEE Transactions on Power Electronics, vol. 30, no. 10, pp. 5650-5664, dec 2015 .
[10] J. G. Davidsen, Y. Yosef-Hay, D. Ø. Larsen, and I. H. H. Jorgensen, "Synthesis and design of a fully integrated multi-topology switched capacitor DC-DC converter with gearbox control," 2017 IEEE Nordic Circuits and Systems Conference (NORCAS): NORCHIP and International Symposium of System-on-Chip (SoC), pp. 1-6, oct 2017. [Online]. Available: http://ieeexplore.ieee.org/document/8124994/

[11] J. F. Dickson, "On-Chip High-Voltage Generation in MNOS Integrated Circuits Using an Improved Voltage Multiplier Technique," IEEE Journal of Solid-State Circuits, vol. 11, no. 3, pp. 374-378, jun 1976.

[12] F. M. Spliid, D. Ø. Larsen, and A. Knott, "Area-Efficiency Trade-Offs in Integrated Switched-Capacitor DC-DC Converters," Nordic Circuits and Systems Conference (NORCAS), IEEE, no. 1, pp. 2-6, nov 2016.

[13] D. J. Perreault, J. H. J. Hu, J. M. Rivas, Y. H. Y. Han, O. Leitermann, R. C. N. Pilawa-Podgurski, A. Sagneri, and C. R. Sullivan, "Opportunities and Challenges in Very High Frequency Power Conversion," IEEE Applied Power Electronics Conference and Exposition, pp. 1-14, feb 2009. [Online]. Available: http://ieeexplore.ieee.org/lpdocs/epic03/wrapper.htm?arnumber=4802625

[14] J. E. Overgaard, J. C. Hertel, J. Pejtersen, and A. Knott, "Application specific integrated gate-drive circuit for driving self-oscillating gallium nitride logic-level power transistors," 2018 IEEE Nordic Circuits and Systems Conference, NORCAS 2018: NORCHIP and International Symposium of System-on-Chip, SoC 2018 - Proceedings, pp. 1-6, oct 2018.

[15] M. Madsen, "Very High Frequency Switch-Mode Power Supplies Miniaturization of Power Electronics," Ph.D. dissertation, 2015.

[16] D. O. Larsen, P. L. Muntal, I. H. Jorgensen, and E. Bruun, "High-voltage pulse-triggered SR latch level-shifter design considerations," NORCHIP 2014 - 32nd NORCHIP Conference: The Nordic Microelectronics Event, pp. 1-6, jan 2015.

[17] Y. Moghe, T. Lehmann, and T. Piessens, "Nanosecond delay floating high voltage level shifters in a $0.35 \mu$ HV-CMOS technology," IEEE Journal of Solid-State Circuits, vol. 46, no. 2, pp. 485-497, dec 2011.

[18] T. M. Andersen, "On-Chip Switched Capacitor Voltage Regulators for Granular Microprocessor Power Delivery,” Doctoral Thesis, ETH Zurich, 2015.

[19] M. D. Seeman, "A Design Methodology for Switched-Capacitor DCDC Converters," Doctoral Thesis, University of California, Berkeley, may 2009.

[20] M. D. Seeman and S. R. Sanders, "Analysis and Optimization of Switched-Capacitor DC-DC Converters," IEEE Transactions on Power Electronics, vol. 23, no. March, pp. 841-851, mar 2008.

[21] T. V. Breussegem and M. Steyaert, CMOS Integrated Capacitive DC-DC Converters. New York: Springer, 2010.

[22] M. S. Makowski, "A note on resistive models of switched-capacitor DCDC converters: Unified incremental-graph-based formulas given," IEEE International Conference on Signals and Electronic Systems, ICSES 2012 - The Conference Proceedings, no. 2561, pp. 2010-2013, sep 2012.

[23] Y. Nour, A. Knott, and L. P. Petersen, "High frequency soft switching half bridge series-resonant DC-DC converter utilizing gallium nitride FETs," 2017 19th European Conference on Power Electronics and Applications, EPE 2017 ECCE Europe, pp. 1-7, sep 2017.

[24] Y. Nour, A. Knott, and I. H. Jørgensen, "Investigating enhancement mode gallium nitride power FETs in high voltage, high frequency soft switching converters," IET Conference Publications, pp. 1-5, apr 2016. 